\title{
In Conversation with Priya Kuriyan: Reflecting on the Personal, Collective and 'Looking Back' in Indian Comics
}

\author{
Aanchal Vij ${ }^{1 *}$
}

Published: April 11, 2020

\begin{abstract}
This interview embodies the dialogue between the personal and the political to the effect that it engages with the interaction between the individual and the collective in the space of (Indian) comics; it explores the trajectory of the comics space through the experiences of Priya Kuriyan and her work.
\end{abstract}

Keywords: comics, Feminist comics, Indian comics, Indian women's comics, nostalgia

\section{INTRODUCTION}

At the International Graphic Novels and Comics Conference (IGNCC) hosted by the University of Bournemouth in 2018, I first thought about the landscape of Indian comics while attending a panel on international comics and nostalgia. The theme of the conference was 'Retro!' and focused on the many relationships that visual narratives share with nostalgia. One of the papers on the panel discussed an Indian graphic novel This Side, That Side (Ghosh 2013), an anthology of visual narratives, edited by Vishwajyoti Ghosh that contains stories about the India-Pakistan partition ${ }^{1}$ and personal stories of memory and longing triggered by the event. This particular conference made me reflect on my own identity as an Indian woman working on American comics in England. This sparked a personal and perhaps nostalgic meditation on the after effects of Partition on my family, on transgenerational memories, and opened up the world of Indian visual narratives that I had little knowledge about, thus far.

From the ideas born out of this self-reflection and conversations with my grandparents about Partition, and a preliminary study of Indian comics, I presented a paper on nostalgia and one of the stories from This Side, That Side at Comics Forum ${ }^{2}$ in September 2018, in Leeds. This is where I met the Indian illustrator and comics artist Priya Kuriyan who was there as a part of a panel to talk about her work within the Indian comics landscape. Priya described herself primarily as a children's book illustrator who stumbled upon comics seven year ago. My interview with her was an engaging insight into her worldview of comics as a medium to express personal reflections but also a space that is symptomatic of its historical times. It was a pleasure to be in conversation with Priya who is an immensely warm person and an especially talented creator. In this narrative, I use my engagement with Priya as a lens to explore the intricacies of the Indian comics space, and also offer an insight into her work that embodies in itself questions surrounding gender, nostalgia, culture and the visual form. This article begins by contextualising Priya's work in the Indian comics space, and moves on to some of her specific works and collaborations to read them as the microcosm of the different movements and expressions developing in the industry as a whole. This paper, just like some of Priya's works, is a reflective practice: it lies at the intersection of my personal contemplation over nostalgia and comics, and a collective understanding of the potential of the comics space in India.

${ }^{1}$ The India-Pakistan partition was the division of British India into India and Pakistan - two independent countries - in 1947 (the same year India gained independence from British rule). The Partition was an outcome of years of cultivated animosity between the Hindus and Muslims in India by the colonial power.

${ }^{2}$ Comics Forum Progress: A Decade of Comics Scholarship, took place in Leeds Central Library on 20-21 September 2018. 


\section{INDIAN COMICS SPACE: AN OVERVIEW}

Much like comics produced in the golden age of US comics that introduced the nation to superheroes such as Superman (DC Comics 1938), Batman (DC Comics 1939) and Captain America (Marvel Comics 1941), the Amar Chitra Katha (ACK) (Pai 1967) were a series of English-language comics developed by Anant Pai in India in 1967 for educational purposes, and to promote various kinds of national myths in India. The American superheroes promoting their nation's heroism is similar to ACK's stories that promised to offer children a 'route to their roots' (Khanduri, 2007: 174) and contained tales about Indian mythology, religion and culture.

In her work, Krishnamurti explores the role of these comics in supporting Hindu nationalist ideologies but, more relevantly, writes that 'for diasporic readers, the texts work at the nexus of popular nationalist ideology, childhood nostalgia, and the construction of concepts of home and identity' (Krishnamurti 2008: vi). I bring these ideas up here to point out the significance of comic books in relation to censorship; for just as comics are increasingly viewed as a space for dissent, opposition and a subculture, they are as much a space for political propaganda. It is therefore necessary to think about the landscape of Indian comics as equally politicised in relation to the feminist discourse. Do the Indian web comics that give voice to women and other feminist comics offer women a space of wish-fulfilment in a way that other forms do not? I find that this sense of wish-fulfilment operates close to a sense of longing, a nostalgia, for a past that is not oppressive after all. Priya's works such as Eat the Sky, Drink the Ocean (Murray 2015) engage with such ideas of a using comics to bend time, reimagining the past and the future to manifest a better world for women.

\section{EARLY WORKS}

Priya is a children's book writer, illustrator, comics maker, director of educational films and animator based in India. A graduate of the National Institute of Design and having published a range of works for children and adults both, it is difficult to put her in a category. Priya's illustration work in several children's books, anthologies, biographies and comics (some of which I will discuss in detail in this article), as she states, has strengthened her belief in the coalescence of image and text in literature. She believes that it makes such literature and data more absorbing and accessible. One of her first few projects was with Toxics Link, an environmental NGO based in Delhi that aims to bring information about environmental toxins into the public domain. ${ }^{3}$ The collective worked in collaboration with Priya to disseminate data and safety information about hazardous substances in an accessible fashion to the Indian urban families and youth; it resulted in a part-fiction, part-factual graphic narrative illustrated by her. In our interview, she explained that the visuals that accompany the text in these narratives make the meaning clearer and more direct. She is reminded of the centuries-old cave paintings in India as a large part of our visual and cultural history. Her ideas on this juxtaposition of image and text related directly to some of the questions I am currently grappling with in my own research on expressing personal and collective longing that, especially, manifests itself in visual narratives. Priya said that 'as a child, everyone is an artist' (P. Kuriyan, personal communication, November 15,2018) and that we have an early understanding of visuals; she believes that there is an urge in everyone to create non-verbally - an urge that we lose as we grow up in a world preoccupied with text rather than images. ${ }^{4}$

\section{INDIRA: POLITICS IN COMICS}

On her work in Indira (Roy 2018) - a graphic memoir of Indira Gandhi, India's first and only female prime minister - Priya spoke candidly about the difference in the reader's narrative or symbolic perceptions of a political figure gathered from, say, a history textbook or a (graphic) narrative form in contrast to using visual art forms. Indira Gandhi is known for her unprecedented centralisation of power in India as she led the war against Pakistan resulting in the formation of Bangladesh (former East Pakistan); she also declared a 21-month long emergency in the country to control civil unrest. ${ }^{5}$ She was assassinated in 1984 by her own bodyguards and even today, generations later, people of India have vastly conflicting opinions about her. Priya's work on Indira (Roy 2018) helped her gain an insight into Indira Gandhi's personal life and contextualised her professional decisions. Historically, Indira Gandhi's role in Indian politics is perceived as problematic to say the least, but Priya points out how a deeper exploration of her personality, childhood and family life, humanised her more and offered another perspective. Priya, in her artwork depicts Gandhi's personality in a more endearing way, emphasising a more

\footnotetext{
3 Toxics Link, Delhi, more information can be found here.

${ }^{4}$ All the quotes by Priya have been taken from my personal interview with her in November 2018 unless cited otherwise.

${ }^{5}$ More on this can be found here
} 
holistic impression of Gandhi that went beyond her contentious political decisions. As pointed out by Bhattacharya in his article, Indira, (Bhattacharya 2018). Much like Marjane Satrapi's Persepolis (2000, 2004), this artwork primarily uses black and white sketches apart from using saturated colours (as in Figure 1) in some of its pivotal moments.

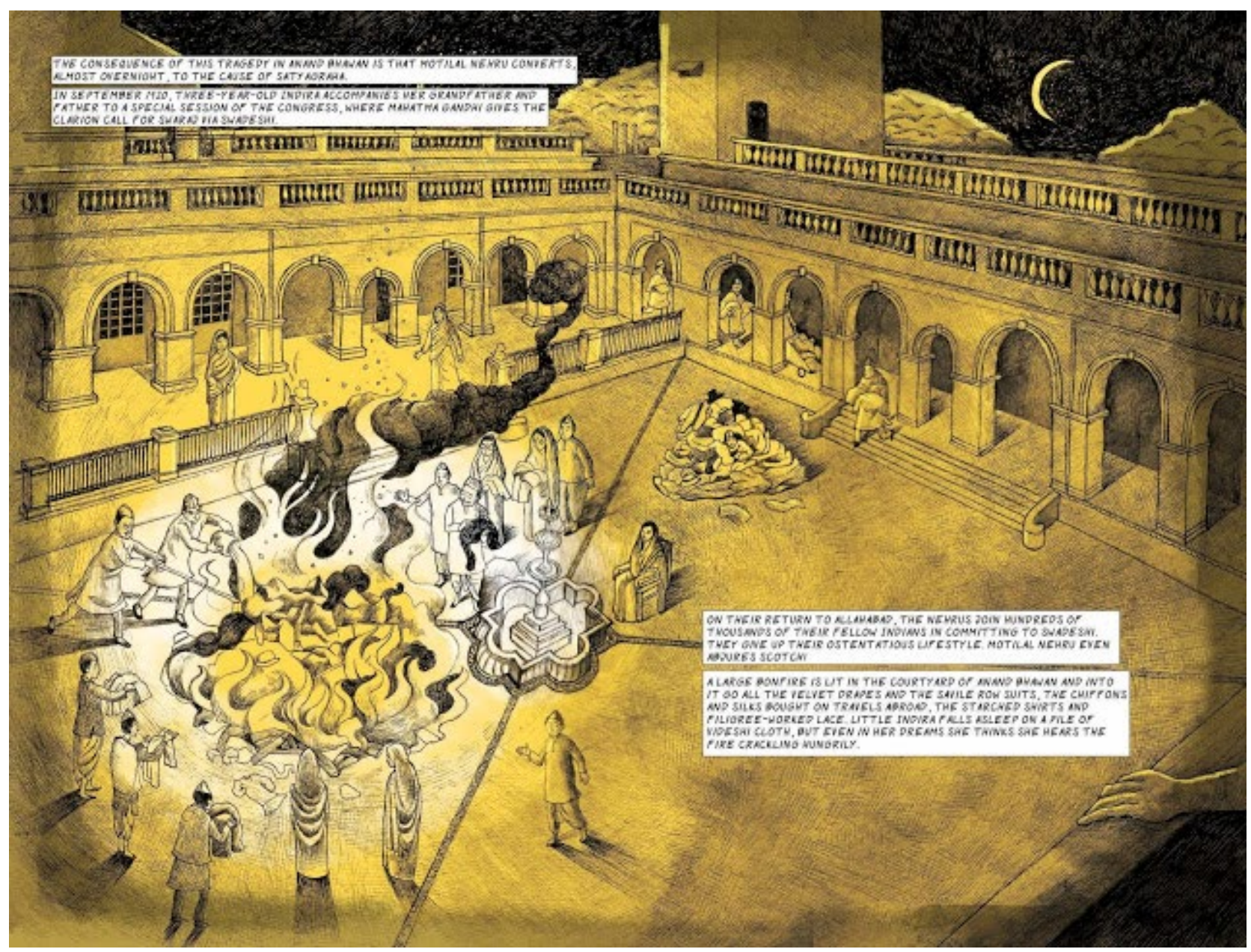

Figure 1. Indira. Devapriya Roy. 2018. (C) Priya Kuriyan.

\section{THE INTERSECTION OF PERSONAL AND POLITICAL}

At this point in our conversation, we spoke briefly about the nuanced relationship between the personal and the political that plays out in the visual space of the comic, and Priya mused that it is 'somehow easier to talk about personal politics through comics because of [the comics'] ability to convey emotions through both text and words' (P. Kuriyan, personal communication, November 15, 2018). She said that the medium is unique even in comparison to say, a film, because the editor of the film has the authority to manipulate the linear sequence of frames or shots as opposed to reading a comic or graphic novel where the readers can view all the panels simultaneously on the page or in a different order. ${ }^{6}$ Coupled with a study of comics, Priya's articulation of the visual form offers us a way to think about how longing as an emotion can be read visually on a page when the panels and graphics disrupt the temporality of reading conventionally. Her work in one of the short stories titled 'The Old Fable' in This Side, That Side (Khair 2013) especially captures this tension between the personal and the political when nostalgia for a time prior to Partition that seems to soak the text, as well as preoccupy the individual characters. The text seems to ask of the reader: What is the significance of looking back as a community? Who looks back at what? (Figure 2).

\footnotetext{
${ }^{6}$ This recalls Svetlana Boym's theorisation of nostalgia in The Future of Nostalgia (Boym 2001), in which she classifies nostalgia into restorative and reflective. Restorative nostalgia that longs to restore the past in the present and disrupt the linearity of time is a kind of spatialising of temporality that in the layout of a comic book is made possible and fluent.
} 

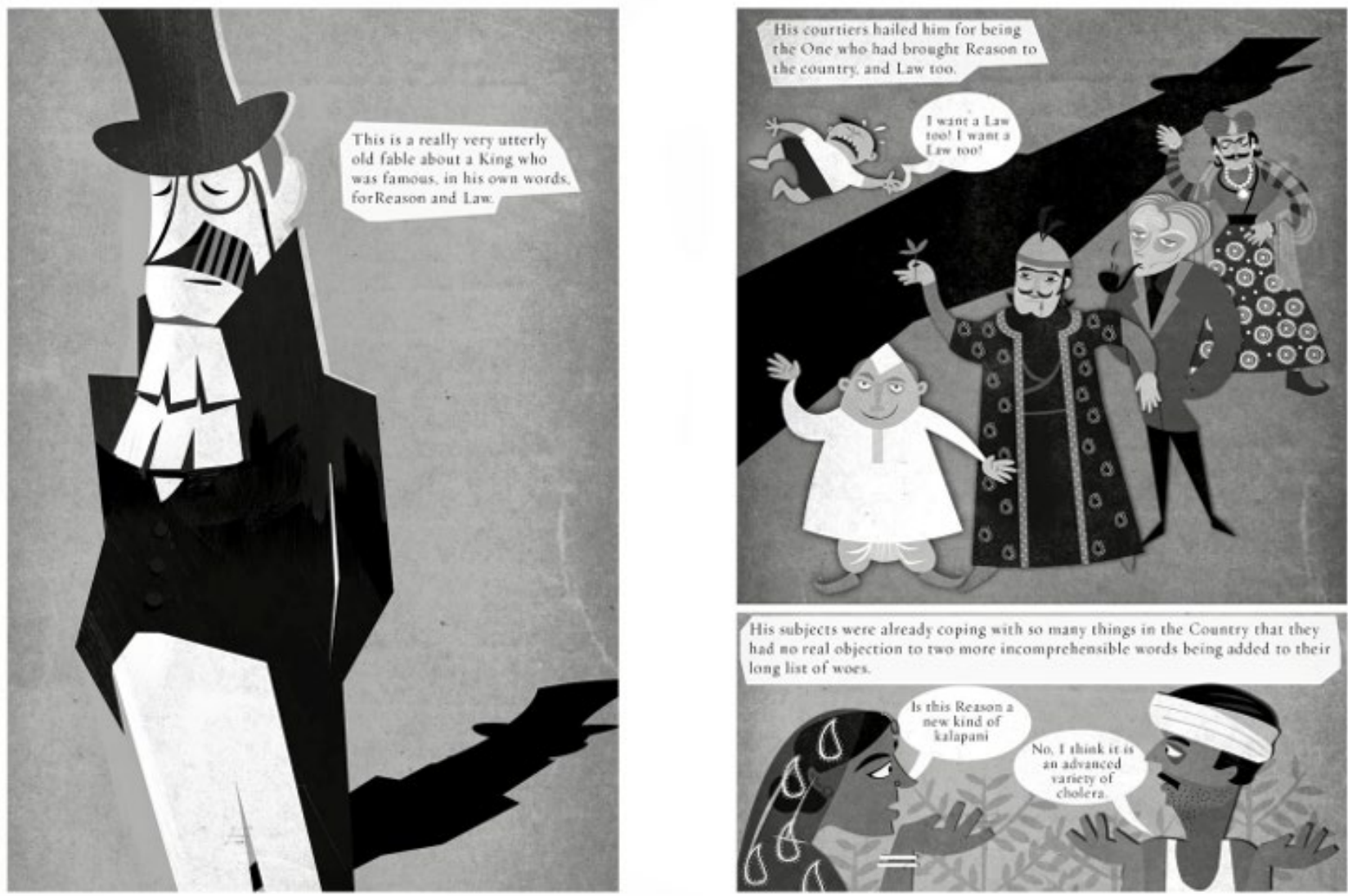

Figure 2. This side, that side. Tabish Khair and V. Ghosh (ed). 2013. (C) Priya Kuriyan.

On the subject of looking back, I asked Priya about a work that is close to her heart and is inspired by her own personal experience, and she answered in a heartbeat: 'Ebony and ivory'(Kuriyan, 2018) her short story from The Elephant in the Room (The Spring Collective 2018) published by (the Delhi-based feminist independent publishing house) Zubaan Books in collaboration with Spring (a feminist collective of women's artists based in Hamburg). Elephant was intended to empower, the project brought together sixteen women from different social and cultural backgrounds to write and draw about their lives. The stories seem to throb with the unique voice of these women, the challenges they faced, and the personal experiences that shaped them. Priya's story is about her relationship with her grandmother that delves not just into her grandmother's personal struggles - becoming a metaphor for generations of women who break conventions in order to offer a more liberating life to the next one - but is a brilliantly reflective story of self-exploration. In our conversation, Priya opened up about looking back at her grandmother and how Priya's own perceptions of her have changed over time. She found the process of writing 'Ebony and ivory' (Kuriyan 2018) refreshing as it allowed her to meditate on her own experiences as a woman that influenced her perception of her grandmother but also quite jarring as she battled with the emotional difficulties that such an engagement with her past, and her fragmented memories, provoked. She spoke about working individually on her story and yet feeling connected to a larger collective as it was created in collaboration with fifteen other women. Elephant brought together sixteen individual stories, in a process of reflective and collective storytelling that created a visual anthology of women-centric narratives of contemporary struggle.

\section{THE LANGUAGE OF VIOLENCE}

This discussion about feminist projects led us to another powerful publication by Zubaan in collaboration with the Toronto-based comics publisher named Ad Astra Comix. This project was initiated after the notorious 2012 gang-rape in Delhi ${ }^{7}$ that Priya rightly described as a 'watershed moment' in India. As one of the editors of the graphic novel titled Drawing the line: Indian women fight back (Kuriyan, Bertonasco and Bartscht 2015), Priya talks about the 'language of violence' (P. Kuriyan, personal communication, November 15, 2018) that changed so heavily after the incident; it brought together thousands of women and men across ages and classes to protest against the brutal gang-rape of a young student Jyoti Singh. The book, an anthology of stories by fourteen women, responded to the tectonic shifts in the public sphere as women were coming out with their own stories of harassment, learning

${ }^{7}$ Gang-rape in Delhi, $16^{\text {th }}$ December 2012. More information about this incident can be found here. 
and unlearning about years of oppression and accumulating a new vocabulary to articulate their own stories. The anthology addresses and responds to the tense social climate at the time in India, especially Delhi, and is a refusal to be silenced about gender based sexual violence. In the afterword of Drawing the Line, Priya succinctly writes,

We all have stories to tell and the difference is really between thinking about it and getting down to actually doing it. In a world that is dominated by stories that are told from the male perspective, I am so thankful for opportunities like this that help young women storytellers bloom' (Kuriyan, Bertonasco and Bartscht 2015: ii).

Her words encapsulate a significant sentiment at a time when more open dialogue about sexual violence within the space of Indian literature is necessary. This work was a result of a week-long workshop where these fourteen women produced a collection of visual narratives that embodied their act of resistance and protest.

\section{COLLABORATIONS}

Priya spoke further about her experiences of working in collaboration with other creators, and projects that she undertook that offered her new opportunities to share her art with creators around the world. One of such projects Eat the Sky, Drink the Ocean (Murray, Dhar and Roy 2015) is a collection of short speculative fictions for which she contributed a short visual prose entitled 'Swallow the moon' (Constable and Kuriyan) along with Kate Constable, an Australian author (Figure 3). On being asked if Priya felt that this project felt distinct from her other works on more non-fictional or children's illustrations or memoir writing, she fondly recollected the experience of creating something deeply personal, or 'true', yet set in an alternate universe. While many of the other creators experimented with dystopian futures, Kate and her story took an exciting detour when their ideas came together. Their fictional world, set in the future, is a utopian one and yet has a very nostalgic component to it. It is a story about rites of passage for women, and while has its dark moments, they are made easier and more digestible with Priya's illustrations. The story pays homage to generations of women, taking stock of the horrors and struggles they have overcome together, it is a narrative of cross-generational gratitude.

This conversation with Priya about speculative world-making enriched my own understanding of the relationship between nostalgia and historical fiction. At this point in my research, I am thinking about how an exploration of a reality that did not take place can inform our understanding of the one that did. This reminds me of some of the stories from This Side, That Side (Ghosh 2013) that engage with the question of 'what if?' to understand the arbitrariness of the timeline that followed Partition. Priya's words about 'messing the timeline' (P. Kuriyan, personal communication, November 15, 2018) and her illustrations in 'Swallow the moon' (Constable and Kuriyan) shed lights on some crucial question about personal and collective histories that occur with the act of looking back.

Priya attributed the relationship between (personal or collective) longing and visual narratives to the association that sequential art has with one's childhood, and even our collective cultural imagination. This reminded me of an excellent talk given by Debanjana Naik (an Assistant Professor at Presidency College, Kolkata) at Transitions, a day-long comics conference hosted by Birkbeck, University of London in August 2018. Naik, whose own research focuses on Indian webcomics and Scott McCloud's 'infinite canvas' (McCloud 2009) (his intention is to delve into questions about identity, gender, sex and more), briefly traced the trajectory of Indian comics in the form of $A C K$. Charts of fruits, vegetables, animals, and so on used to be part of primary school educational work, they came in the form of cheap comics that were typically sold at roadside stalls and railways stations. Through reflecting on this history of comics, Priya arrived at a discussion of contemporary webcomics in India as a new subcultural form of production, and she discussed some of the popular ones such as Royal Existentials (Parthasarathy and Krishnan 2014) and Sanitary Panels (Taneja 2014). ${ }^{8}$ Her talk brought back memories for me of reading hundreds of comics as a child; in hindsight, it made me realise how much Indian visual narratives have been part of my life. Priya's illustrations and ideas on the personal and collective are reminiscent of Naik's work because they underscore the inconspicuous everyday nature of reading graphic narratives for Indians, and, consequently, an instinctively nostalgic association with them.

8 https://www.royalexistentials.com/; https://sanitarypanels.com/about/

(C) 2020 by Author/s 


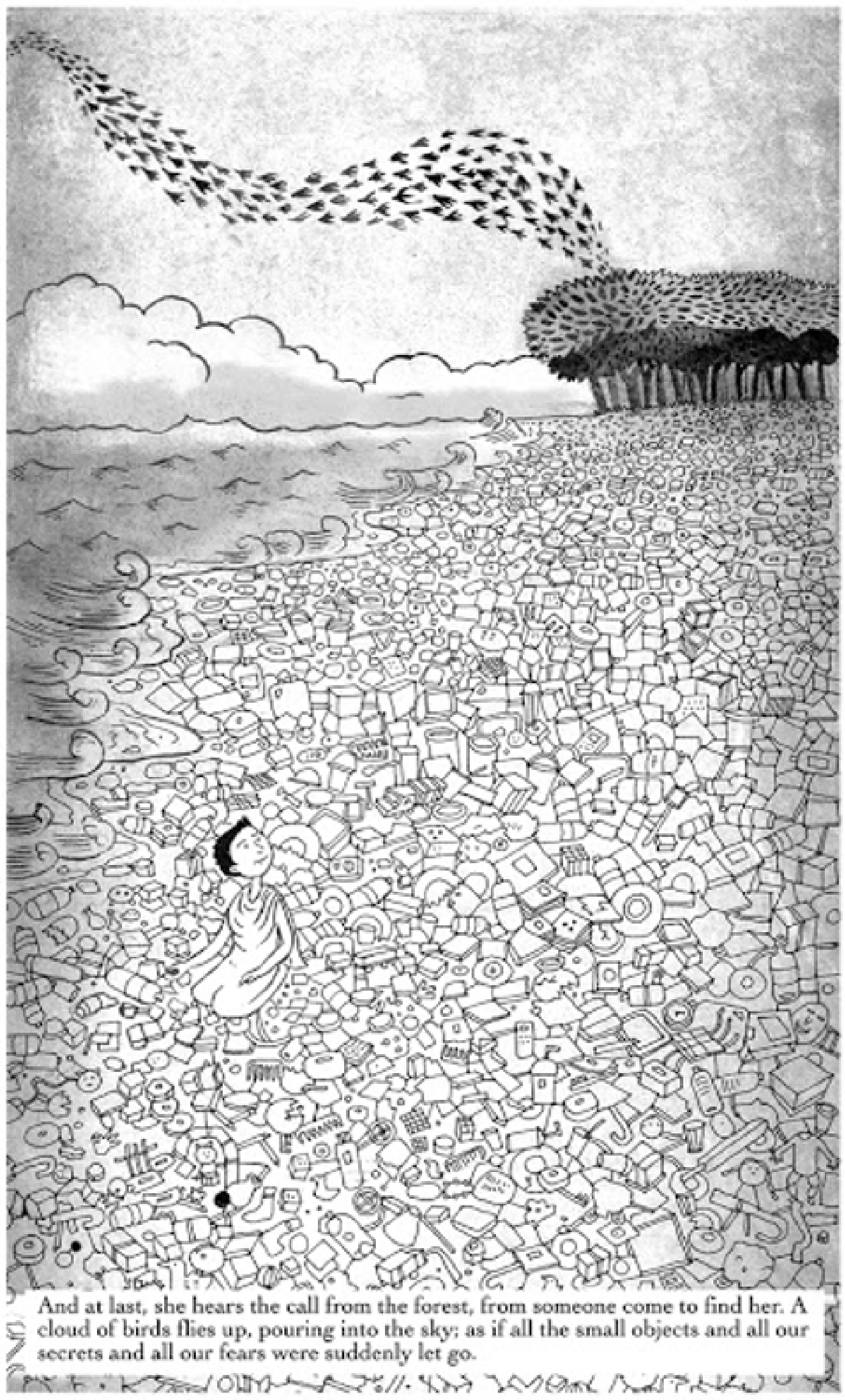

END

Figure 3. 'Swallow the moon' from Eat the Sky, Drink the Ocean. Kate Constable and Priya Kuriyan. 2015. C Priya Kuriyan. 
I shared some of Naik's ideas with Priya and asked her what she thought of Indian webcomics as a 'subculture' that has the potential to subvert the mainstream political discourse, in the nationalist climate of India. She laughed and said that the comics community in India is so small that it is a subculture in itself. Unsurprisingly, this led to an exchange about the potential sanitisation of content and censorship that accompanies an artist's work in these contemporary nationalistic times. She said that she has felt the difference in the work she has undertaken for government or corporate funded projects as opposed to those for independent publishing houses. But that said, she mused that some level of self-censorship is inevitable and perhaps slips in involuntarily given the volatile times we live in, and for better or for worse, arguing that the comics community generally manages to stay under the radar and escape censorship anyway. Priya claimed that she found the visual form incredibly liberating. According to her, while pre-censorship and self-censorship of one's creative endeavours is a reflection of the times one inhabits, there is a lot of original work being done by independent publishing houses like Zubaan and Yoda Press. She briefly talked about webcomics and we discussed some of our favourite ones and excitedly came to the realisation that many of these webcomics were, in fact, female-centric and feminist-run such as Sanitary Panels (Taneja 2014). It is crucial to think about the contribution of such webcomics to the Indian discourse of feminism as well as other intersectional feminist issues relating to class, caste, religion, sexuality and other bases of discrimination.

\section{RECEPTION ABROAD}

Towards the end of our discussion, I asked Priya about her recent travels to the UK and the reception of her work here compared to India, having attended conferences and residencies, and shared her work widely. She said that while some of her works such as Indira (Roy 2018) sparked curiosity in her peers since many had no context about Indira Gandhi's life and personality, and remarked that people responded to it with a desire to know more. She felt that a work like Indira (Roy 2018) is a good first step toward forming a more nuanced judgment about her character. Some of her other works such as 'Ebony and ivory' (Kuriyan 2018) were more widely discussed because they are central to the prolific relationship between the personal and the collective, a theme that is widely recognised and identified with by feminists and activists. We approached the end of our conversation as we briefly discussed what she imagined the future of Indian comics and visual narratives will look like. She was positive that in the last 5-7 years more and more people have been opening up to the potential of the comic genre. She believes that selfpublishing is going to be the next big thing in India for a variety of independent creators. She talked about the comic festivals happening in Bangalore and Pune and the steadily increasing affinity there towards comics. She remarked that while the community interested in graphic and comic art is increasing, and she has faith in its continued growth, it is still a very small percentage of the global media consumption.

\section{CONCLUSION}

This conversation with Priya brought forth some potent themes central to the landscape of Indian comics. It informed my ongoing study of nostalgia and myth-making in contemporary American comics and culture and offered me an opportunity to readjust and locate the theoretical framework of my own research within the Indian context of visual narratives. It was a privilege to speak to Priya and I believe, in some ways, her own work embodies the features she ascribes to the comics world: her own work encounters a complex engagement with nostalgia, with the composition of the personal against the collective and, most importantly, with the identity politics of being a woman in the comics industry.

\section{REFERENCES}

Bhattacharya, B. (2018). A graphic biography of India's Iron Lady: Indira Gandhi. Livemint, 25 ${ }^{\text {th }}$ March. Available at: https://www.livemint.com/Leisure/kXfWywBfavJJ73EeVcGRsI/A-graphic-biography-of-Indias-IronLady-Indira-Gandhi.html (Accessed 16 February 2020).

Boym, S. (2001). The future of nostalgia. New York: Basic Books.

Constable, K. and Kuriyan, P. (2015). Swallow the moon. In P. Dhar, K. Murray and A. Roy (eds.), Eat the Sky, Drink the Ocean (pp. 14-32). Delhi: Zubaan Books.

Dhar, P., Murray, K. And Roy, A. (eds.) Eat the Sky, Drink the Ocean. Delhi: Zubaan Books.

Khair, T. (2013). The old fable. In V. Ghosh (ed.) This Side, That Side, (pp. 15-29). Delhi: Yoda Press.

Khanduri, R. G. (2010). Comicology: Comic books as culture in India. Journal of Graphic Novels and Comics, 1(2), 171-191. https://doi.org/10.1080/21504857.2010.528641 
Krishnamurti, S. V. (2008). 'The route to your roots': History, Hindu Nationalism, and Comics in India and South Asian Diasporas (Dissertation submitted for D.Phil.), York University, Canada.

Kuriyan, P. (2018). The Elephant in the Room. In the Spring Collective. Delhi: Zubaan Books.

Kuriyan, P. Bertonasco, L. and Bartscht, L. (2015). Drawing the Line: Indian women fight back!! Ontario: Ad Astra Comix.

Kuriyan, P. (2018, November 15). Telephonic interview.

McCloud, S. (2009) The infinite canvas, Scott McCloud. Available at: http://scottmccloud.com/4inventions/canvas/ (Accessed 14 January 2020).

Parthasarathy, A. and Krishnan, C. (2014). Royal Existentials. Falana Films.

Roy, D. (2018). Indira. Delhi: Context.

Satrapi, M. (2000, 2004). Persepolis. Paris: L'Association.

Tabish, K. (2013). The old fable, in V. Ghosh (ed) This Side, That Side. Delhi: Yoda Press.

Taneja, R. (2014). Sanitary Panels. Facebook. Available at: https://sanitarypanels.com/about/

The Spring Collective. (2018). The Elephant in the Room. Delhi: Zubaan Books.

Citation: Vij, A. (2020). In Conversation with Priya Kuriyan: Reflecting on the Personal, Collective and 'Looking Back' in Indian Comics. Feminist Encounters: A Journal of Critical Studies in Culture and Politics, 4(1), 16. https://doi.org/10.20897/femenc/7920 